\title{
The Effects of Subsurface Irrigation on Current and Subsequent Year's Growth in Shadscale
}

\author{
PATRICIA S. JOHNSON AND BRIEN E. NORTON
}

\begin{abstract}
Sursurface irrigation of individual Atriplex confertifolia (shadscale) plants was implemented in the field during the summer of 1976 through the use of vertical access tubes to a depth of $50 \mathrm{~cm}$. Shoots were marked on control and watered plants and examined periodically by enumerating every leaf, bud, flower, fruit, and second-order stem. Plant response to subsurface irrigation as determined in the fall enumeration revealed a modest increase in stem length and leaf weight and summer production of lateral branches. The carryover effect of summer irrigation was reflected in new growth on shoots of watered plants in spring 1977 being more than twice the production of shoots on controls. The 1976 response to subsurface irrigation is thought to be carbohydrate storage and/or root development. Watering did not enhance bud or shoot survival overwinter.
\end{abstract}

The inhibition of cambial activity is commonly attributed to the action of hormones (Rubenstein and Nagao 1976, McKell and Willard 1974). Other factors that have been shown to inhibit cambial activity include water stress (Rubenstein and Nagao 1976, McIntyre 1976, Avila et al. 1975, Waisel 1970, Wardlaw 1969, Fahn et al. 1968), light intensity, and nutrition (Rubenstein and Nagao 1976). Water and available nutrients are usually limiting for extended periods in regions of the arid western part of North America. Among these constraints, water is generally regarded as the most limiting resource.

Effective utilization of random summer rainfall events is dependent on timing of responses so as to optimize growth and survival under a generally arid regime (Noy-Meir 1973). Stem elongation in shadscale (Atriplex confertifolia (Tor. \& Frem.) S. Wats.), a halophytic shrub of the Great Basin desert, is largely confined to spring months under natural

\footnotetext{
Authors are research technician and associate professor, Department of Range Science, Utah State University, Logan 84322 .

This research was supported through the US/IBP Desert Biome Program; additional funding was also provided by the Utah State University.

Manuscript received March 3, 1979.
}

conditions. At this time soil water potential is relatively high due to moisture recharge of the soil profile from snowmelt (Caldwell et al. 1977). Summer precipitation in semiarid areas results in an increased soil water potential only in the surface layers, which dry quickly if further rain is not immediately forthcoming. Summer storms do not stimulate additional shoot growth of shadscale, even when these storms are augmented by surface irrigation (J.A. MacMahon unpublished data, Hodgkinson et al. 1978). Root growth, however, continues through the summer deep in the soil profile (Fernandez and Caldwell 1975, Holthausen 1977).

The inherent quiescence of the shoot system in summer can be interpreted as an adaptive mechanism to the aridity of the season, thereby avoiding the cost of responding to erratic and short-lived soil water impulses. If, however, water stress is responsible for the inhibition of shoot growth and bud elongation, relief of that stress should induce growth. Since shadscale is better able to use water from deep in the soil profile than from near the surface during the summer (Johnson and Norton 1979), surface watering is probably not effective as an ameliorating treatment.

In this study an attempt was made to experimentally disturb the quiescent status of the shrub by subsurface irrigation and to record subsequent response under field conditions. We hypothesize that reducing summer water stress of shadscale will (1) stimulate above-ground growth during the season of treatment, (2) favor the retention and development of vegetative and reproductive parts, and (3) increase production the following spring.

\section{Site and Methods}

The study was conducted at the U.S. International Biological Program (US/IBP) Desert Biome intensive study site in Curlew Valley, near Snowville, Utah. The area has been described in detail by Balph (1973). The study site is co-dominated by shadscale and big sagebrush (Artemisia tridentata Nutt.); squirreltail (Sitanion 
hystrix (Nutt.) J.B. Smith) is the major grass species associated with these shrubs. Crucifers and chenopods contribute the bulk of a sparse annual plant component. Mean elevation at the site is $1,320 \mathrm{~m}$ and soils are primarily silty loams. Mean annual precipitation is $230 \mathrm{~mm}, 60$ to $70 \%$ of which comes during winter.

\section{Shoot Enumeration Technique}

A method similar to that used by West and Fareed (1973) was developed to describe individual marked stems by identifying and recording all buds, leaves, flowers, fruits, and second-order stems and their relative locations on the shoot. The following terms describing shoot parts will be used throughout this paper as they are defined below and illustrated in Figure 1.

Immature buds-buds with leaves up to $1 \mathrm{~mm}$ long.

Mature buds-buds with leaves more than $1 \mathrm{~mm}$ long but with no internodal elongation.

Mature leaves-leaves which subtend an axillary bud and are found on elongated stems.

Bud leaf pairs-pairs of leaves of similar size, apparently opposite each other in the mature bud but upon stem elongation separated by an internode. Since several bud leaf pairs may occur in one mature bud, the individual pairs were designated as primary, secondary, etc., according to their vertical position in the bud.

First-order stem - the main stem of a shoot, originating from a bud on the previous year's stem.

Second-order stem-a stem originating from buds on the

first-order stem of the current year's shoot growth.

The primoidial leaves appear to be opposite; during shoot elongation, however, differential growth and twisting of the stem distort the pairing pattern and increase the distance between leaves of each pair so as to generate a spiralling arrangement (Fig. 1). Due to the irregularity in leaf placement, an arbitrary vertical line, running

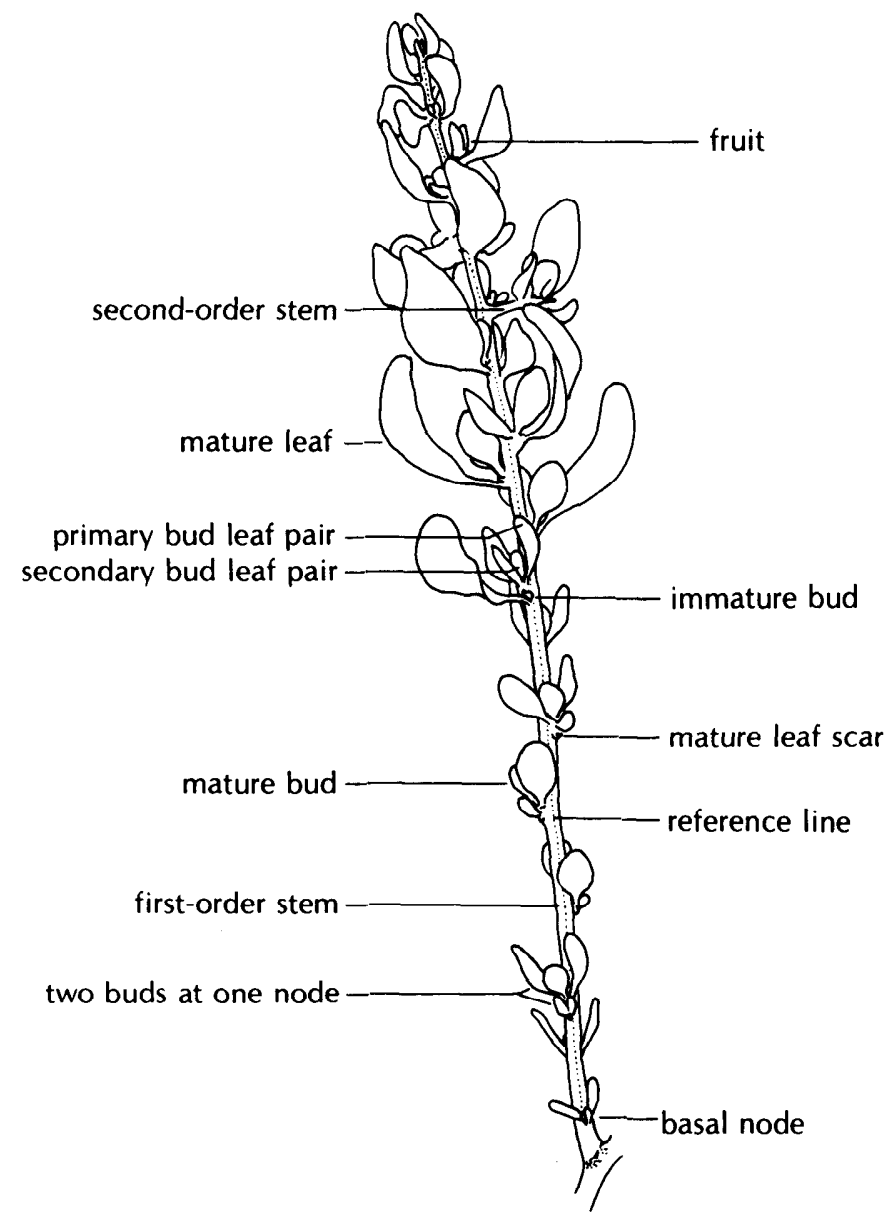

Fig. 1. Diagram of a current year's shadscale shoot. from the basal node to the tip of the stem, was used as a reference line in the enumeration process. The nodes were grouped into sets, each set beginning with a node closest to the reference line and including all successive nodes (moving toward the top) between it and the next node near the line. The enumeration began at the base of the stem and ended at the apex, and each node was enumerated in order within its set. The enumeration of second-order stems was separate from that of the first-order stem, and was done in the same fashion.

\section{Watering Treatment}

During the spring of 1976 a field population of shadscale plants was located, all of approximately the same size within a 1-hectare portion of the study site. Pairs of plants of similar size, in the same shoot length class (short, medium, and long) and of identical sex were identified in the field; one member of the pair was randomly assigned to a watering treatment and the other was designated as control, until there were ten plants in a group. Male and female plants of each shoot length class were represented in the two groups. This procedure of plant selection which provided matching individuals in the control and treated experimental populations, was necessary in order to analyze the data statistically using pairwise methods.

Three white polyurethan pipes (diameter $2.5 \mathrm{~cm}$ ) were installed around each of the watered plants but not the controls. The pipes were buried vertically to depths of 15,30 , and $50 \mathrm{~cm}$ and were located $10 \mathrm{~cm}$ to the north, west, and south of the plant, respectively. Gravel was poured into the pipes to a depth of about $2 \mathrm{~cm}$ to reduce the erosive impact of the watering; the pipes were capped to prevent direct evaporation. Irrigation was confined to these pipes and usually occurred once a week from May 26 to September 13; up to $500 \mathrm{ml}$ of water were poured into each pipe on each water day. The total amend ment averaged 21.8 liters per plant. Assuming a soil water utilization zone of $25 \mathrm{~cm}$ radius from the taproot, if the irrigation water had fallen as rainfall it would be equivalent to approximately $110 \mathrm{~mm}$, which is more than the average precipitation over the same summer period.

Ceramic-cup thermocouple psychrometers (manufactured by Wescor, Inc.) were buried in a vertical line $10 \mathrm{~cm}$ from the east side of two plants per treatment at depths of $10,25,45$, and $60 \mathrm{~cm}$. These were read at dawn with a Wescor MJ 55 microvoltmeter periodically through the summer, immeditely before irrigation. The psychrometers were also read twice in 1977, on April 29 and June 28. Prior to installation, each psychrometer was calibrated with $\mathrm{NaCl}$ solutions (Brown 1970).

Pressure bomb readings of plant water stress for both control and watered plants were taken at dawn approximately every two weeks (Scholander et al. 1965, Waring and Cleary 1967). These measurements occurred approximately 1 week after the last application of water and immediately before the next irrigation. Readings were taken on three to four stems for both control and watered treatments at each sampling date.

Four stems on each control and watered plant were chosen and marked with lengths of colored thread. A complete enumeration of the marked stems occurred four times: at the end of the spring growth period in June 1976; in October 1976; prior to spring growth in April 1977; the fourth occasion was the end of the spring growth period 1977 , but did not include an enumeration of the new 1977 stems. One unmarked stem (representing less than $2 \%$ of the current year's shoot growth) was harvested from each of the 10 control plants for leaf, fruit, and stem analysis at the time of the first enumeration in 1976. Stem lengths were measured and leaves, and fruits, and stems were dried for two days at $80^{\circ} \mathrm{C}$, and weighed. Half the marked stems were harvested from every plant at the end of the second enumeration in October 1976. Leaves and fruits were separated from the stems, leaves were sorted according to their leaf classification, and all stems were measured for length. All leaves, fruits, and stems were dried at $80^{\circ} \mathrm{C}$ for two days and weighed. The remaining marked stems were harvested after the final enumeration in June 1977. Leaves and flowers were separated from the 
stems, the length of the stems measured, and all were dried for two days at $80^{\circ} \mathrm{C}$ and weighed.

\section{Results}

\section{Shoot Morphology}

Current year's stems of shadscale plants originate from buds located on first-order stems of the immediately preceding year. Second-order branches are often produced in the spring and are located on the distal half of the first-order stem. Stems are highly variable in appearance from plant to plant due to variations in both total stem and internodal lengths; such variation is much less, however, among stems of an individual shadscale plant. Mature leaves subtend one or several buds at a node; the mature leaves are larger, and the axillary buds are generally more developed, on the more basal portions of each first-order stem. Individual shadscale stems were studied, using the enumeration process, over a year of seasons, resulting in the following phenological notes on morphology.

By late spring 1976 (June), stem elongation had ceased and both male and female plants were in flower. Flowers of both sexes were generally confined to the distal half of the first-order stem, as were all second-order stems. Secondorder stems, when they occurred, were the major sites of flowers. Mature leaves were abundant on the first-order stems and, at more proximal locations, were often reddish in color. First- and second-order stem tips were hardening into spines at the time.

In the autumn of 1976 (October) several changes had occurred. Many of the mature leaves had fallen, especially from the proximal portions of the stems. Half the buds on spring growth had died over summer. New second-order stems had developed, usually from mature buds occurring below the second-order stems present at the end of spring. Occasionally several buds at one node would develop into second-order stems. The second-order stems which developed during the summer were vegetative in contrast to the reproductive second-order stems formed in the spring. Terminal spines were completely hardened by autumn, and the distal, reproductive half of each stem was usually dying or dead.

An average of about 60 percent of the shoots and 47 percent of the buds on surviving shoots died overwinter; the watering treatment conferred no special advantage in terms of shoot or bud retention.

There was very little new growth present at the early spring 1977 enumeration, April 29, even though temperatures seemed favorable for growth. The winter was very dry with little water recharge of the soil profile. Most early 1977 growth was limited to enlargement of buds on the proximal half of the 1976 stems and production of additional bud leaf pairs. Flowers were completely absent.

Forty-one $\mathrm{mm}$ of rain occurred between April 25 and May 22 (about half of which fell on May 6) followed by a flush of spring growth. The 1977 stems sampled in late spring originated on the proximal half of the 1977 stem, always occurring below the reproductive portion of the 1976 shoots. An average of about three 1977 shoots were produced on each 1976 stem on both watered and control plants.

\section{Watering Treatment}

Data from the spring 1976 enumeration of the 40 marked stems were used to compare the watered and control groups
Table 1. Initial comparison (spring, 1976) of watered and control plant populations, ten plants per group, before treatment application.

\begin{tabular}{lcc}
\hline \hline Category & Watered ${ }^{2}$ & Control \\
\hline First-order stem length $(\mathrm{mm})$ & 50.5 & 51.3 \\
Functional nodes' per mm first-order stem & 0.44 & 0.45 \\
Second-order stems per shoot & 1.1 & 1.5 \\
\hline
\end{tabular}

'A functional node is defined as one with an apparently living axillary bud ${ }^{2} \mathrm{~A}$ significance test $(p<.05)$ revealed no difference between the watered and control groups.

prior to treatment (Table 1). Of the three parameters chosen, none showed a significant difference between the watered and control groups.

The soil water potential $\left(\Psi_{\mathbf{s}}\right)$ curves are shown in Figure 2 according to psychrometer depth. Psychrometers were located at least $15 \mathrm{~cm}$ from irrigation tube outlets, and were usually read six or seven days after the last irrigation event. Even though the psychrometer record therefore depicts the driest soil conditions under irrigated plants, at each depth the average $\Psi_{\mathrm{s}}$ (average of all values over the watering season) was significantly wetter $(P<.025)$ for watered plants.

Plant water potential $\left(\Psi_{\mathrm{pl}}\right)$ was recorded on eight occasions from July through September, 1976. The average $\Psi_{\mathrm{pl}}$ of watered plants ( -40 bars) was significantly higher $(P<.05)$ than the average $\Psi_{\mathrm{pl}}$ of the controls ( -60 bars).

At the time of the autumn 1976 enumeration and harvest there were no differences in individual or total fruit weights,

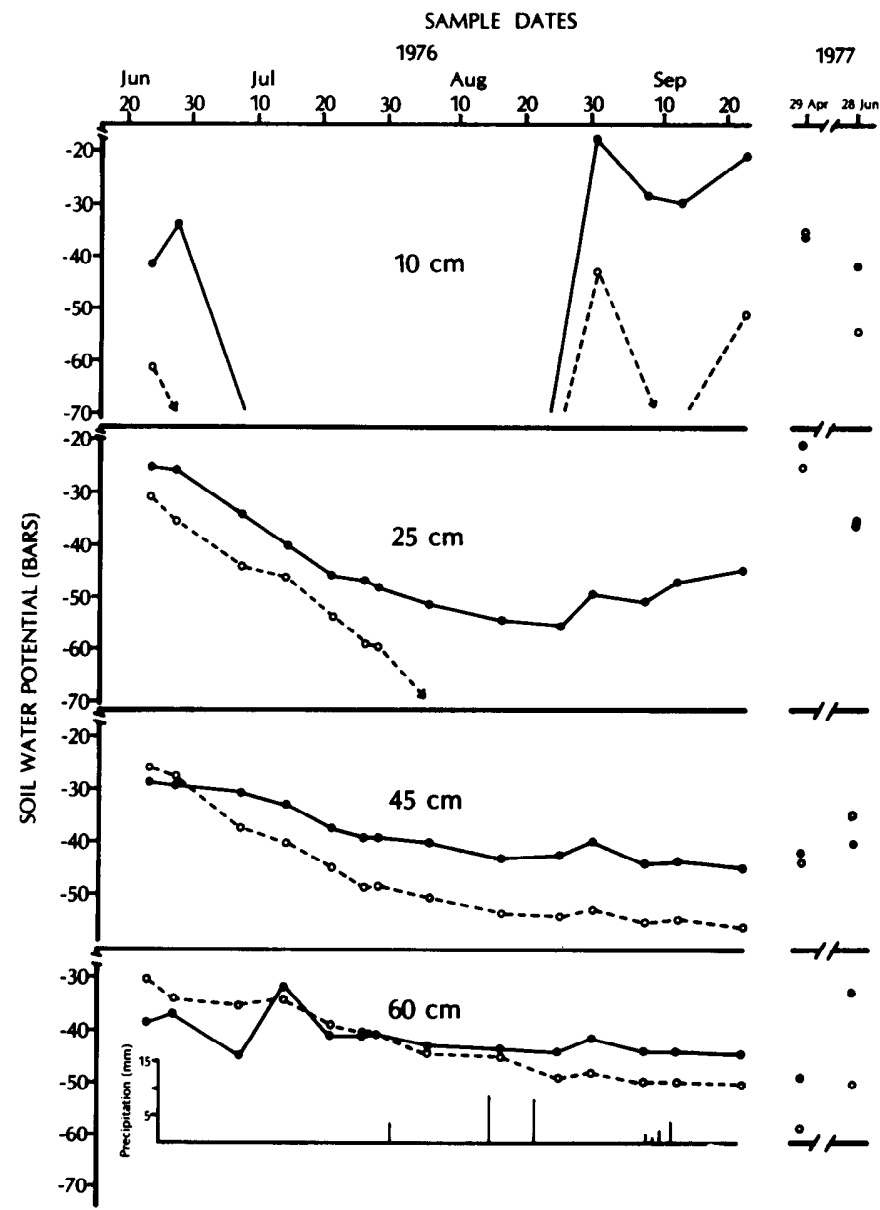

Fig. 2. Soil water potentials (bars) at four depths below watered (-) and (control (----) plants during the 1976 watering treatment and at two dates in 1977. Data points are means of two replicates. 
Table 2. Shadscale shoot measures comparing the watered and control plants at the autumn 1976 and spring 1977 sample dates. Data from the spring 1976 pretreatment samples are included to show changes during the summer water season.

\begin{tabular}{|c|c|c|c|c|c|c|c|}
\hline \multirow[b]{2}{*}{ Shoot Measurements } & \multicolumn{2}{|c|}{ Spring 1976} & \multicolumn{2}{|c|}{ Autumn 1976} & \multicolumn{2}{|c|}{ Spring 1977} & \multirow[b]{2}{*}{$P \leq$} \\
\hline & Watered & Control & Watered & Control & Watered & Control & \\
\hline Leaf $\mathrm{wt} / \mathrm{mm}$ stem $(\mathrm{mg} / \mathrm{mm})$ & & $2.0 \mathrm{a}$ & $1.7 \mathbf{a}$ & $1.3 \mathrm{~b}$ & & & .05 \\
\hline Functional nodes/mm first-order stem & $0.44 \mathrm{a}$ & $0.45 \mathrm{a}$ & $0.30 \mathrm{~b}$ & $0.24 c$ & & & .05 \\
\hline Individual leaf wt (mg) & & & 2.92 & 2.39 & & & .05 \\
\hline Individual fruit wt (mg) & & & 1.5 & 1.4 & & & \\
\hline Total fruit wt (mg) & & & 32.7 & 18.9 & & & \\
\hline Stem elongation per four shoots $(\mathrm{mm})$ & & & 14.5 & 9.2 & & & .05 \\
\hline Leaf retention ${ }^{1}$ & & & 0.34 & 0.13 & & & .025 \\
\hline New second-order stems per four shoots & & & 1.5 & 0.8 & & & .01 \\
\hline Leaf wt/mm first-order stem $(\mathrm{mg} / \mathrm{mm})$ & & & & & 2.5 & 3.5 & .05 \\
\hline Production per 1976 shoot $(\mathrm{mg})$ & & & & & 221.1 & 91.4 & .05 \\
\hline 1977 leaf wt per 1976 shoot $(\mathrm{mg})$ & & & & & 172.9 & 79.7 & .1 \\
\hline 1977 stem wt per 1976 shoot $(\mathrm{mg})$ & & & & & 45.4 & 11.0 & .05 \\
\hline 1977 stem length per shoot $(\mathrm{mm})$ & & & & & 83.8 & 27.2 & .1 \\
\hline
\end{tabular}

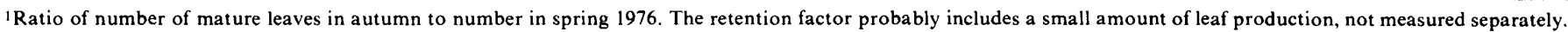

but leaves of watered plants were on average a little larger than leaves on control plants (Table 2). Stem elongation, mainly expressed in growth of second-order stems, was greater in watered than control plants. Watered plants also had greater retention and/or production of mature leaves, which could have accounted for the greater average leaf weight. Leaf weight per $\mathrm{mm}$ stem was not significantly different between late spring and autumn sampling dates for watered plants; the same parameter showed significant decline over the same period for control plants. The number of functional nodes per mm first-order stem declined from spring to autumn, 1976, for both watered and control plants. More functional nodes died on the control plants, however, than on the watered plants.

The most dramatic results of the 1976 watering treatment were seen in the spring of 1977 , following a very dry winter. Production per 1976 shoot (average 1977 new growth of leaf, stem, and fruit produced on each 1976 stem) of watered plants was more than twice that of the controls. Leaf weight per $\mathrm{mm}$ stem, however, was greater in the controls than in watered plants. The control plants produced $46 \%$ of the leaf weight and only $32 \%$ of the stem length of watered plants, reflecting a concentration of leaf material on the control plant stems with shorter internodal elongation.

\section{Discussion}

Subsurface irrigation generated only a slight response in shadscale production during the season of treatment application. Stems of watered plants grew significantly more than those of controls (Table 2), but the magnitude was quite small in both cases, with stems growing an average of only 3.6 to $2.3 \mathrm{~mm}$ on watered and control plants, respectively.

Leaf drop, partial or total, is a common drought survival mechanism used by many desert species (Noy-Meir 1973, Cunningham and Strain 1969). While shadscale does not drop all its leaves during the summer dry season, a substantial number of mature leaves are discarded (Table 2). Shoots of watered plants had significantly more leaves, and heavier leaves, than shoots of control plants in the autumn; the watering treatment enhanced either retention of mature leaves or production of new leaves, or both.

The winter of 1976-77 was very dry. Total precipitation at the Snowville station, $2 \mathrm{~km}$ from the study site, was $34 \mathrm{~mm}$ for the months of November through March, compared to a long-term mean of $115 \mathrm{~mm}$ for the same period. In spite of the dry winter, or perhaps because of it, the greatest effect of the 1976 summer watering treatment on above-ground production occurred in spring 1977 (Table 2). The 1977 production on each surviving 1976 shoot from watered plants was more than double that on each 1976 control shoot. Internodal elongation was greater on watered shoots than controls; this indicates that control plants devoted a greater percentage of their available carbon to production of photosynthetic tissue than did the watered plants. By the same token, it would appear that watered plants were able to invest a surplus carbon supply into high energy-cost materials such as lignin in stems.

Since spring is the season of maximum shoot growth, differences in growth between the springs of 1976 and 1977 were expected due to the drought preceding the 1977 season. A comparison of shoot production between the two years was devised to assess the degree of growth depression and the influence of the summer watering regime. No direct measurement of 1976 spring production was taken; values were therefore obtained indirectly. Two measures of production were used: leaf weight and total shoot weight. The 1977 leaf weight and total shoot weight were obtained by harvest in June 1977. For 1976 production the following equation was used:

$$
X=Y Z
$$

where $Z$ is the total spring 1976 stem length of 39 shoots, and $Y$ is the leaf weight per $\mathrm{mm}$ stem or shoot weight per $\mathrm{mm}$ stem. The results are presented in Table 3 .

Of the 80 stems that were marked in the spring of 1976,41 were harvested in autumn 1976, leaving 39 shoots for perennation. (The uneven division was the result of the accidental harvest of one extra shoot.) Twenty of the 39 shoots came from watered plants; nineteen were on control plants. Both controls and watered plants suffered approximately $60 \%$ mortality of their 1976 shoots over winter, and each remaining shoot produced approximately three 1977 shoots. Winter bud loss amounted to $80 \%$ total $(60 \%$ shoot death and $50 \%$ bud death on surviving shoots) compared to $50 \%$ summer mortality of vegetative and floral buds combined, which suggests that winter trauma is a greater constraint on bud survival than the impacts of the dry summer season. Over-winter shoot death was due to rodent herbivory and 
Table 3. Comparison of total spring 1976 and spring 1977 production for 39 shoots marked in 1976 on watered and control plants.

\begin{tabular}{|c|c|c|c|c|c|c|}
\hline \multirow[b]{2}{*}{ Treatment } & \multicolumn{3}{|c|}{ Spring 1976} & \multicolumn{3}{|c|}{ Spring 1977} \\
\hline & $\mathrm{n}$ & $\begin{array}{c}\text { Total shoot wt } \\
\text { (g) }\end{array}$ & $\begin{array}{c}\text { Total leaf wt } \\
(\mathrm{g})\end{array}$ & $\mathbf{n}$ & $\begin{array}{c}\text { Total shoot wt } \\
\text { (g) }\end{array}$ & $\begin{array}{c}\text { Total leaf wt } \\
(\mathrm{g})\end{array}$ \\
\hline Shoots from watered plants & 20 & 2.8 & 2.0 & 9 & 2.0 & 1.56 \\
\hline Shoots from control plants & 19 & 2.8 & 2.0 & 7 & 0.6 & 0.56 \\
\hline
\end{tabular}

associated damage and natural sacrifice, by the plant, of entire branches or branch systems.

The seven control shoots left alive in spring 1977 produced less than $21 \%$ of the total shoot weight and $28 \%$ of the total leaf weight of the original 19 shoots marked in spring 1976. This year-to-year difference represents a substantial decline in photosynthetic capacity for each control plant. The nine watered-plant shoots remaining alive after winter produced about $71 \%$ of the total shoot weight and $78 \%$ of the leaf weight of the 20 shoots originally present in spring 1976. The summer watering treatment obviously produced a higher photosynthetic capacity for plants the following year than did the control situation.

Since the major response to irrigation appeared the year following the treatment, we presume that either the soil moisture improvement due to watering carried over to the next spring, or else that there was an immediate impact from the watering in the form of greater development of the root system or increased carbohydrate storage potential, or both. It is apparent in Figure 2 that soil water potentials under controls and treated plants converged between September 24 and April 29, at least to a depth of $45 \mathrm{~cm}$, which may represent the maximum penetration of recharge from snowmelt. Treatment response would, therefore, seem to be a function of plant physiological parameters. A large percentage of the carbon budget is devoted to the root system in shadscale (Caldwell et al. 1977), and an increase in root density following surface watering has been observed in summer (Hodgkinson et al. 1978). Enhanced development of the root system due to summer subsurface irrigation
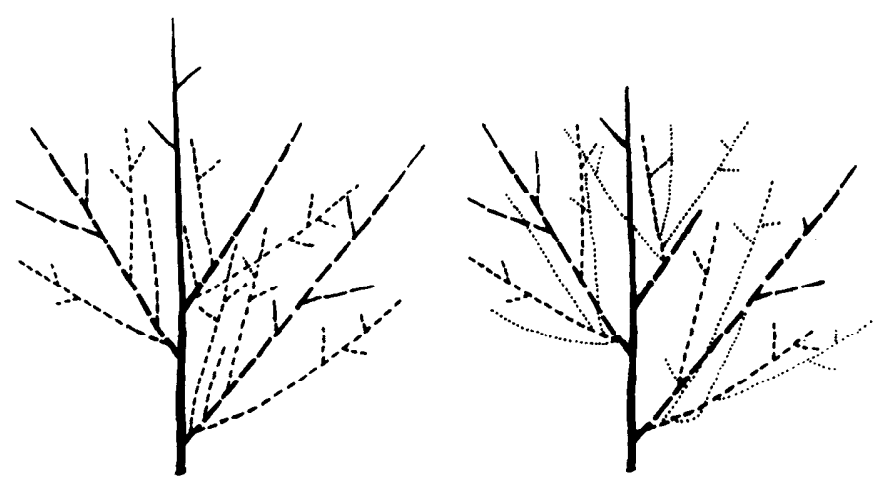

WITH NEW 1976 GROWTH WITH NEW 1977 GROWTH

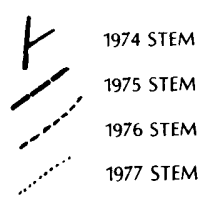

Fig. 3. Diagram of hypothetical 1974 shoot (left) with spring 1976 growth: same 1974 shoot (right) in spring 1977 indicating stem losses over the year and new 1977 growth. could increase water uptake the next spring, assuming roots produced in response to irrigation remain viable.

The seasonal pattern of total available carbohydrates (TAC) in relation to growth stage for shadscale was described by Coyne and Cook (1970). There is normally a TAC drawdown early during the spring growth period and a gradual buildup as the shoots mature. A second drawdown occurs in late summer, primarily due to fruit development; autumn regrowth has been reported for this species (Coyne and Cook 1970, Love and West 1972) and may also contribute to the drawdown. A rapid replenishment of TAC then follows. It is likely that summer subsurface irrigation increases the TAC buildup by maintaining greater leaf biomass and lower plant water stress than the control situation. These TAC stores could then be responsible for the increased production of watered plants the following spring.

Shadscale replaces its photosynthetic material yearly, with the current year's growth originating from the previous year's stems. The basic growth patterns were not altered with watering and are represented diagramatically in Figure 3. There is an apparent division of each first-order stem according to function. The distal half is reproductive; this part of the stem seems physiologically determinate and incapable of generating new vegetative growth once elongtion has terminated and the stem begins to harden. All second-order stems are also determinate and die. The proximal half is vegetative in function; it is in this stem region that buds mature and second-order vegetative stems develop over summer. The proximal region is the only source of perennating buds, which develop within the protective shell of old spiny branches. Heavy grazing during the summer can be severely detrimental to these shrubs (Cook and Stoddard 1963); however, the presence of terminal spines on stems is useful in discouraging grazing of leaves and developing fruits (Holmgren and Hutchings 1972). Flower location on the distal half of the stems facilitates wind pollination; fruits are more easily disseminated from that location by wind and animal disturbance.

\section{Conclusions}

Substantial aboveground growth response to summer watering of shadscale was delayed until the following spring. Immediately after the season of subsurface irrigation a relatively small advantage in vegetative parts was measured, but no change due to watering could be detected in reproductive material. The advantage was partly a function of new growth, including stem elongation and branch extension, and partly a function of greater retention of leaves generated in the spring.

Marked differences were obtained between control and summer-watered plants when production was measured the following spring. Growth in 1977 on shoots of watered plants was $71 \%$ of 1976 spring shoot biomass, but only $21 \%$ of 1976 spring biomass in the case of controls. This differ- 
ence is manifest in total shoot weight, especially stem material, but not shoot numbers; watering did not enhance bud and shoot survival overwinter.

Resistance to summer growth when water stress is reduced is a reflection of the determinate growth pattern of shadscale. Shoot growth generally ceases at the end of spring, as shoot apices harden and lower leaves senesce. The distal part of the shoot is devoted to reproductive activity and dies when the fruits are mature, creating a defense of terminal spines for the overwintering buds. The proximal portion of the shoot remains vegetative and is the sole source of active growth buds the following spring. This critical resource of buds could be depleted if summer watering stimulated branch growth of second-order stems that degenerate into dead spines.

\section{Literature Cited}

Avila, G., M.E. Aljaro, S. Araya, G. Montenegro, and J. Kummerow. 1975. The seasonal cambium activity of Chilean and Californian shrubs. Amer. J. Bot., 62: 473-478.

Balph, D.F. 1973. Curlew Valley validation site report. US/IBP Desert Biome Res. Memo. RM 73-1. 336 p.

Brown, R.W. 1970. Measurement of water potential with thermocouple psychrometers: construction and applications. USDA Forest Serv. Res. Pap. INT-80, 27 p. Intermountain Forest and Range Exp. Sta., Ogden, Utah.

Caldwell, M.M., R.S. White, R.T. Moore, and L.B. Camp. 1977. Carbon balance, productivity, and water use of cold desert shrub communities dominated by $\mathrm{C}_{3}$ and $\mathrm{C}_{4}$ species. Oecologia, 29: 275-300.

Cook, C.W., and L.A. Stoddart. 1963. The effect of intensity and season of use on the vigor of desert range plants. J. Range Manage. 16: 315-317.

Coyne, P.I., and C.W. Cook. 1970. Carbohydrate reserve cycles in eight desert range species. J. Range Manage., 23: 438-444.

Cunningham, G.L., and B.R. Strain. 1969. An ecological significance of seasonal leaf variability in a desert shrub. Ecology, 50: 400-408.
Fahn, A., Y. Waisel, and L. Benjamin. 1968. Cambial activity in Acacia raddiana Sari. Ann. Bot., 32: 677-686.

Fernandez, O.A., and M.M. Caldwell. 1975. Phenology and dynamics of root growth of three cool semi-desert shrubs under field conditions. J. Ecol., 63: 703-714.

Hodgkinson, K.C., P.S. Johnson, and B.E. Norton. 1978. Influence of summer rainfall on root and shoot growth of a cold-winter desert shrub, Atriplex confertifolia. Oecologia, 34: 353-362.

Holmgren, R.C., and S.S. Hutchings. 1972. Salt desert shrub response to grazing use. In: C.M. McKell, J.P. Blaisdell, and J.R. Goodin (eds.). Wildland shrubs - their biology and utilization. USDA Forest Serv. Gen Tech. Rep. INT-1. 494 p. Intermountain Forest and Range Exp. Sta., Ogden, Utah.

Holthausen, R.S. 1977. Seasonal course of root respiration in Atriplex confertifolia. M.S. thesis, Utah State University, Logan. 54 p.

Johnson, P.S., and B.E. Norton. 1979. Partitioning the soil profile to measure shadscale response to water at different depths. Soil Sci. 128: 121-125.

Love, L.D., and N.E. West. 1972. Plant moisture stress patterns in Eurotia lanata and Atriplex confertifolia. Northwest Sci., 46: 44-51.

McIntyre, G.I. 1976. Apical dominance in the rhizome of Agropyron repens: the influence of water stress on bud activity. Can. J. Bot., 2747-2754.

McKell, C.M., and E.E. Willard. 1974. Rangeland shrub regrowth: bane or benefit? Utah Science, 35:34-36

Noy-Meir, I. 1973. Desert ecosystems: environment and producers. Annu. Rev. Ecol. and Syst., 4: 25-51.

Rubenstein, B., and M.A. Nagao. 1976. Lateral bud outgrowth and its control by the apex. Bot. Rev., 42: 83-113.

Scholander, P.F., H.T. Hammel, E.D. Bradstreet, and E.A. Hemmingsen. 1965. Sap pressure in vascular plants. Science, 148: 339-346.

Waisel, Y., N. Liphschitz, and A. Fahn. 1970. Cambial activity in Zygophyllum dumosum Boiss. Ann. Bot., 34: 409-414.

Wardlaw, I.F. 1969. The effect of water stress on translocation in relation to photosynthesis and growth. Il. Effect during leaf development in Lolium temulentum L. Aust. J. Biol. Sci., 22: 1-16.

Waring, R.H., and B.D. Cleary. 1967. Plant moisture stress: evaluation by pressure bomb. Science, 155: 1248-1254.

West, N.E., and M. Fareed. 1973. Shoot growth and litter fall processes as they bear on primary production of some cool desert shrubs. US/IBP Desert Biome Res. Memo. RM 73-9. Utah State Univ., Logan. 13 p.

\section{Membership in the Society for Range Management. .}

is open to those engaged in or interested in the study. management, or use of range ecosystems and the intelligent use of all range resources

includes research scientists, ranchers, governmental agency administrators and technical personnel, teachers, students, and people from the business community

provides members with two publications-one oriented to research (Journal of Range Management) and the other oriented to practical resource management (Rangelands) offers opportunities for face-to-face exchange of ideas at local, national, and intemational meetings of the Society.

Dues vary according to type of membership and geographical section. For application forms and additional information, contact the:

Executive Secretary

Society for Range Management

2760 West Fitth Avenue

Denver, Colorado 80204

(303) 571-0174 